\title{
Effect of pH on Hemicellulose Extraction and Physicochemical Characteristics of Solids during Hydrothermal Pretreatment of Eucalyptus
}

\author{
Zeguang Yang, ${ }^{\text {a,b }}$ Liming Cao, ${ }^{\mathrm{a}, \mathrm{b}}$ Yan Li, ${ }^{\mathrm{a}, \mathrm{b}}$ Min Zhang, ${ }^{\mathrm{a}, \mathrm{b}}$ Fanyan Zeng, ${ }^{\mathrm{a}, \mathrm{b}}$ and \\ Shuangquan Yao ${ }^{\mathrm{a}, \mathrm{b}, *}$
}

The effects of $\mathrm{pH}$ on residual solids (RS), total dissolved solids (TDS), carbohydrates, and lignin in eucalyptus during hydrothermal pretreatment were studied. The balance between RS and TDS was obtained at $\mathrm{pH} 4.0$ in hydrothermal pretreatment with pre-adjustment $\mathrm{pH}$. The yield of hemicellulose increased, and oligosaccharides dominated. Hemicellulose had the highest dissolution rate, and cellulose and lignin had the lowest dissolution rate at $\mathrm{pH}$ 4.0. The crystallinity index (Crl) and structural transformation of lignin was analyzed by X-ray diffraction (XRD) and nuclear magnetic resonance spectroscopy (NMR) with or without pretreatment. The $\mathrm{Crl}$ at $\mathrm{pH} 4.0$ was $64.2 \%$ higher than that with the traditional hydrothermal pretreatment (62.1\%). The $\beta-\mathrm{O}-4$ bonds, OMe, and phenylcoumarane of lignin were protected. The highest hemicellulose extraction and minimal physicochemical structural changes were obtained at $\mathrm{pH}$ 4.0.

Keywords: Eucalyptus; Hydrothermal pretreatment; Pre-adjustment pH; hemicellulose; Lignin

Contact information: a: School of Light Industrial and Food Engineering, Guangxi University, Nanning, 530004, PR China; b: Guangxi Key Laboratory of Clean Pulp \& Papermaking and Pollution Control, Nanning, 530004, PR China; *Corresponding author: yaoshuangquan@ sina.cn

\section{INTRODUCTION}

The efficient extraction of hemicellulose is a prerequisite for high value utilization of woody biomass. Hemicellulose has been extracted by many different methods, i.e., chemical (Jiang et al. 2014; Zhang et al. 2016; Liu et al. 2018), physical (Chandra et al. 2015), biological (Kaur et al. 2016; Zhou et al. 2020), and combined pretreatments (Amidon and Liu 2009). Hydrothermal pretreatment is one of the main physical pretreatment methods (Zhuang et al. 2016; Goldmann et al. 2017). It has the advantages of low energy consumption, low requirement for chemical substances, little influence on physicochemical structure, and high recovery rate of hemicellulose (Yao et al. 2015, 2017; Ge et al. 2020).

The extraction efficiency of hemicellulose is affected by temperature, time, and solid-to-liquid ratio during hydrothermal pretreatment. Li et al. (2010) studied the effects of time and temperature on the extraction of hemicellulose from mixed hardwood (maple, poplar, birch). The results showed that $11.0 \%$ xylan was removed at $170{ }^{\circ} \mathrm{C}$. Cebreiros et al. (2018) studied the effects of liquid ratio and temperature on extraction of hemicellulose from eucalyptus; the removal rate of hemicellulose was $61.0 \%$ at $160{ }^{\circ} \mathrm{C}$ and solid-to-liquid ratio 1:6. The oligomer in the reaction solution was $10.2 \mathrm{~g} / \mathrm{L}$. Thus, the best effect of traditional hydrothermal pretreatment (THP) for hemicellulose extraction varies with the raw materials (Liu et al. 2012). A hydrothermal pretreatment with pre-adjustment to $\mathrm{pH}$ 
4.0 greatly improves the hemicellulose extraction efficiency of bagasse because the dissolution and degradation of cellulose and lignin are inhibited (Yao et al. 2015). The physicochemical structure of residual solids (RS) is less affected. Thus, it is important to study whether this new hydrothermal pretreatment method has wide applicability to different materials.

In this paper, the effect of $\mathrm{pH}$ on cellulose, hemicellulose, and lignin contents during hydrothermal pretreatment of eucalyptus was studied. The degradation and dissolution of main components were analyzed. The structural changes in cellulose and lignin with or without pretreatment were analyzed by x-ray diffraction (XRD) and nuclear magnetic resonance spectroscopy (NMR).

\section{EXPERIMENTAL}

\section{Materials}

Eucalyptus chip was purchased from local factories (Tianjing, China). It was dried and cut into $50 \mathrm{~mm} \times 4 \mathrm{~mm}$ samples. The chemical composition of eucalyptus chip was analyzed by NREL methods (Huang et al. 2020). The results are shown in Table 1.

Table 1. Chemical Composition of Eucalyptus (\%)

\begin{tabular}{|c|c|c|c|}
\hline Cellulose & Hemicellulose & AlL & ASL \\
\hline 44.70 & 24.00 & 23.42 & 3.67 \\
\hline
\end{tabular}

AIL: acid insoluble lignin; ASL: acid soluble lignin

\section{Methods}

A six-pot digester with a rotating function (Green Wood, Greenwood County, USA) was used. Eucalyptus chips (oven dry $50 \mathrm{~g}$ ) were first mixed with water $(250 \mathrm{~mL})$ and then placed in the reactor. The $\mathrm{pH}$ (3.0 to 5.0) of the pretreatment solution was adjusted by sodium hydroxide or acetic acid. The maximum heating temperature was $170{ }^{\circ} \mathrm{C}$, which was held for $60 \mathrm{~min}$. The reaction solution was collected after the reaction was terminated by cold water (Yao et al. 2015).

Eucalyptus fiber was analyzed with or without pretreatment by two-step acidolysis, as described previously (Huang et al. 2020).

The mixture collected at the end of the reaction was centrifuged, and the supernatant was passed through a $0.22 \mu \mathrm{m}$ membrane filter (Whitfield et al. 2016). Further hydrolyzed products were obtained by adding $99.80 \%$ concentrated sulfuric acid into the reaction solution and reacting for $1 \mathrm{~h}$ at $121{ }^{\circ} \mathrm{C}$. The sugar content in the reaction (glucose, xylose, arabinose, galactose, and mannose) and further hydrolysates were analyzed by ion chromatography (IC) (THERMO, Waltham, USA) (Sluiter et al. 2012).

The RS, hydrolysates, and a small amount of insoluble residues were obtained by hydrothermal pretreatment. The hydrolysate was centrifuged at $10000 \mathrm{rpm}$ for $10 \mathrm{~min}$ and collected. The total dissolved solids (TDS) were obtained after freeze drying.

The crystallinity of raw material (RM) and RS was analyzed by XRD (LTD, City, Japan) with the following parameters: $\mathrm{CuKa}(\lambda=1.5406 \mathrm{~A})$; voltage, $40 \mathrm{v}$; current, $35 \mathrm{~mA}$; scanning range, $2 \theta=5$ to $45^{\circ}$; and scanning speed, $5 /{ }^{\circ} \mathrm{min}$. The crystallinity index was calculated (French and Cintron 2013).

The lignin in the RM and RS were separated by enzyme treatment and weak acid 
hydrolysis (Yuan et al. 2011). Spectra were recorded at $25{ }^{\circ} \mathrm{C}$ on a Bruker MSL-300 spectrometer (Karlsruhe, Germany). A total of $40 \mathrm{mg}$ lignin was dissolved in $0.7 \mathrm{~mL}$ of DMSO-d6 solution.

\section{RESULTS AND DISCUSSIONS}

\section{Content Change of RS and TDS}

The RS and TDS are important indexes to evaluate the effect of pretreatment. Woody biomass has different final $\mathrm{pH}$ values of reaction mixture in THP. The effects of $\mathrm{pH}$ on RS and TDS in hydrothermal pretreatment were studied. The final $\mathrm{pH}$ value was 3.0, 3.6, 4.0, 4.5, and 5.0, respectively. Other reaction conditions were a solid-to-liquid ratio of $1: 5$, temperature of $170^{\circ} \mathrm{C}$, and time 60 of min. The results are shown in Fig. 1 .

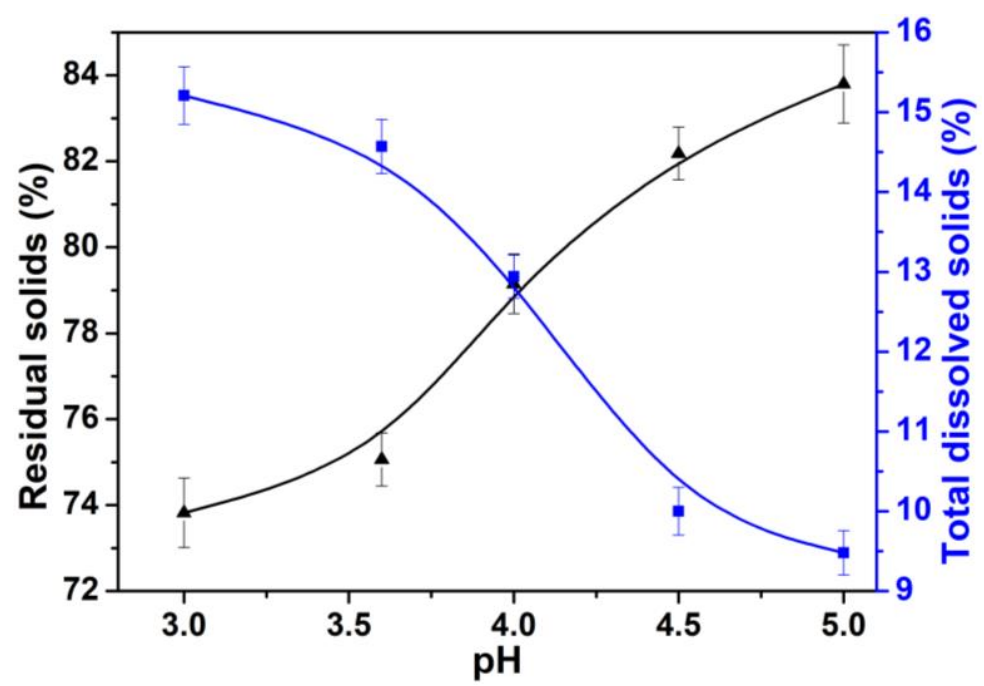

Fig. 1. Effects of $\mathrm{pH}$ on RS and TDS in hydrothermal pretreatment

The yield of RS increased with the increasing $\mathrm{pH}$, from $73.8 \%$ at $\mathrm{pH} 3.0$ to $83.8 \%$ at $\mathrm{pH}$ 5.0. However, the yield of TDS decreased with increasing $\mathrm{pH}$, from $15.2 \%$ at $\mathrm{pH} 3.0$ to $9.5 \%$ at $\mathrm{pH} 5.0$. Hence, the dissolution and degradation of carbohydrates and lignin were intensified by the increasing acidity. The final $\mathrm{pH}$ value of reaction liquid from THP was 3.6. The yield of RS and TDS was $75.1 \%$ and $14.6 \%$, respectively. At $\mathrm{pH} 4.0$, the yield of RS increased to $79.1 \%$, but TDS decreased to $14.6 \%$. The yield of RS increased, while the yield of TDS decreased slightly at $\mathrm{pH}$ 4.0. The balance between RS and TDS was obtained at $\mathrm{pH} 4.0$ in hydrothermal pretreatment with pre-adjustment $\mathrm{pH}$.

\section{Dissolution of Three Major Compositions}

The changes in RS and TDS were mainly caused by variations in the cellulose, hemicellulose, and lignin contents. The extraction efficiency and solid quality are directly affected by the change in the dissolution rate of these components. Therefore, the effects of $\mathrm{pH}$ on the dissolution rate of hemicellulose, cellulose, and lignin were studied. The final $\mathrm{pH}$ of the reaction liquid was $3.0,3.2,4.0,4.5$ or 5.0. The other pretreatment conditions were the same as the above experiments. The results are shown in Fig. 2. 


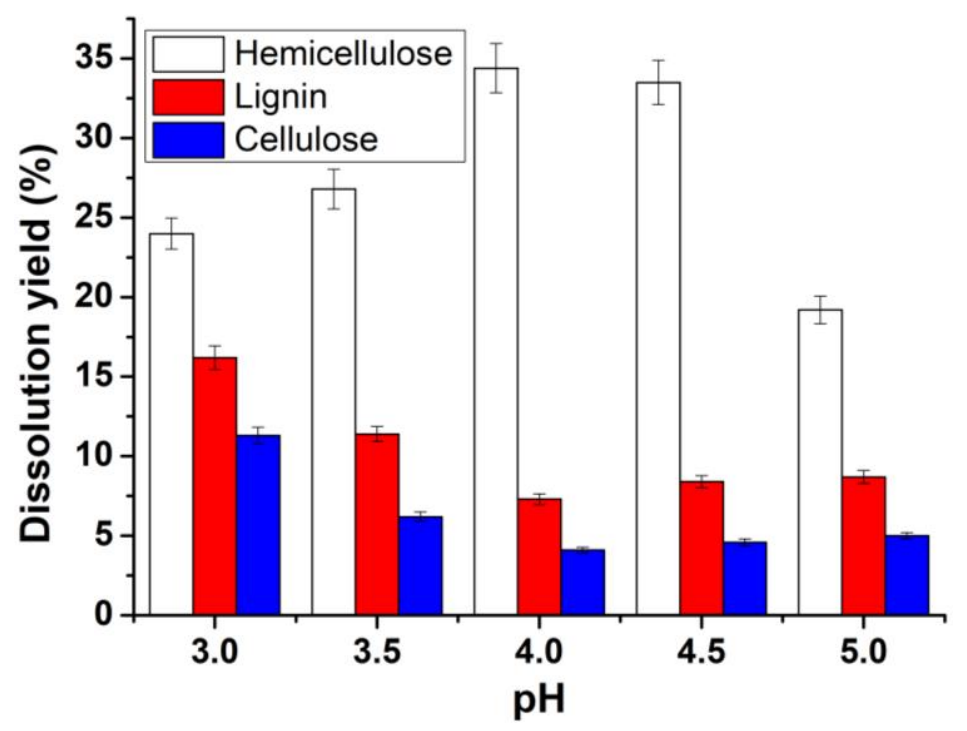

Fig. 2. Effects of $\mathrm{pH}$ on the dissolution yield of hemicellulose, cellulose and lignin

The dissolution yield of hemicellulose was $24.0 \%$ at $\mathrm{pH} 3.0$. It decreased by $34.4 \%$ at $\mathrm{pH}$ 4.0. It started to decrease when the $\mathrm{pH}$ was greater than 4.0 and decreased to $19.2 \%$ at $\mathrm{pH}$ 5.0. This result reflects that the fracture of glycosidic bonds of hemicellulose was promoted at $\mathrm{pH}$ 4.0. The dissolution of hemicellulose was promoted (Yao et al. 2017). The dissolution of hemicellulose is usually accompanied by the dissolution and degradation of cellulose. However, in these experiments, the dissolution of cellulose was the lowest at $\mathrm{pH}$ $4.0(4.5 \%)$. The results showed that the dissolution of cellulose was inhibited at $\mathrm{pH}$ 4.0.

In addition to carbohydrate dissolution, a small amount of lignin was dissolved during hydrothermal pretreatment. Under acidic conditions, the $\alpha-\mathrm{O}-4$ and $\beta-\mathrm{O}-4$ bonds in lignin undergo homolytic cleavage (Batalha et al. 2015), releasing aromatic compounds (Santos et al. 2018) and dissolving them in the reaction solution. In addition, a part of lignin is dissolved in AIL in the form of lignin-carbohydrate complexes (Trajano et al. 2013). The dissolution rate of lignin was the lowest at $\mathrm{pH} 4.0$, similar to cellulose. This suggests that the dissolution and degradation of lignin was inhibited at $\mathrm{pH}$ 4.0. This was attributed to the effect of $\mathrm{pH}$ on the degradation of components, condensation, and deposition of dissolved substances in the pretreatment process (Chen et al. 2010). Similar to acidic hydrolysis of cellulose, the glycosidic bonds of hemicellulose break in an acidic medium, leading to degradation of hemicellulose. But the structural differences between hemicellulose and cellulose lead to differences in the breaking of glycosidic bonds. Uronic acid ligands are the most difficult to dissolve due to the effect of hydroxyl on the stability of glycosidic bonds. As a result, the stability of cellulose glycoside bonds is greater than that of hemicellulose glycosidic bonds. Therefore, the breaking of hemicellulose glycosidic bonds and cellulose glycosidic bonds was different at $\mathrm{pH}$ 4.0. Compared with THP (pH 3.6), the dissolution of hemicellulose was promoted, while the dissolution of cellulose and lignin was inhibited in hydrothermal pretreatment with pre-adjustment $\mathrm{pH}(\mathrm{pH} 4.0)$. 


\section{Sugar Content Analysis}

The separation and purification of the effective components of hydrolysate is affected by the ratio of oligomers and monosaccharides. The effects of $\mathrm{pH}$ on the yield of total sugars, oligose, and monose in hydrolysates were studied. The availability of hydrolysate components was evaluated. Other conditions of pretreatment were the same as the above experiments. The results are shown in Fig. 3.

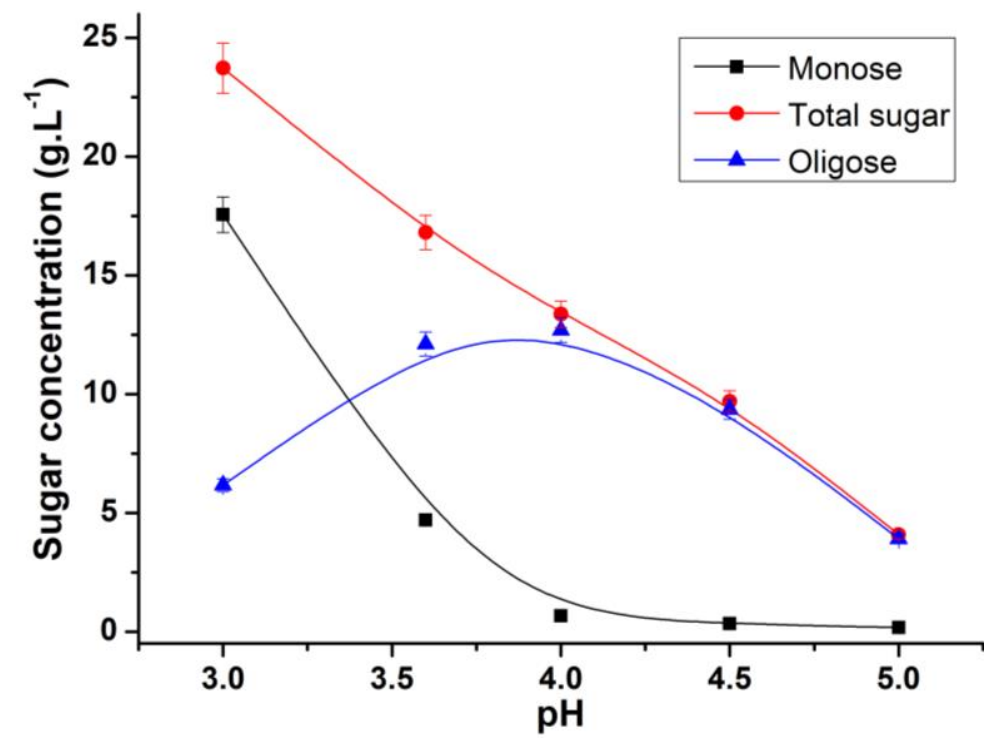

Fig. 3. Effects of $\mathrm{pH}$ on the yield of monose, oligose, and total sugar from eucalyptus

The total sugar concentration decreased from 23.7 to $4.1 \mathrm{~g} / \mathrm{L}$ with increasing $\mathrm{pH}$. The monose concentration rapidly decreased from $\mathrm{pH} 3.0$ to $0.67 \mathrm{~g} / \mathrm{L}$ at $\mathrm{pH} 4.0$. It was almost unchanged between $\mathrm{pH} 4.0$ to 5.0. The highest oligose concentration was $12.7 \mathrm{~g} / \mathrm{L}$ at $\mathrm{pH}$ 4.0. The total sugar concentration was similar to that of monose, but the oligose was the lowest at $\mathrm{pH}$ 3.0. This result suggests that the ability to convert oligose to monose increases with increasing acidity. The total amount of hemicellulose extracted at this time was large, but most hemicellulose was in the form of monose, which is not conducive to the separation and purification of components. The concentration of monose decreased with increasing $\mathrm{pH}$, indicating that oligose degradation was inhibited. At the same time, the total sugar concentration was reduced. This result demonstrated that hemicellulose extraction was inhibited. However, the monose concentration increased to its maximum value at $\mathrm{pH}$ 4.0. At $\mathrm{pH} 4$, hemicellulose was present as oligose. The results were consistent with previous studies, showing that larger molecular weight hemicellulose was obtained by buffer solution at pH 4.0 (Persson et al. 2009; Song et al. 2011). The extraction efficiency of hemicellulose was the highest at $\mathrm{pH} 4.0$ in hydrothermal pretreatment with pre-adjustment $\mathrm{pH}$. This is consistent with previous studies on bagasse (Yao et al. 2015). The results show that the hydrothermal pretreatment with pre-adjustment $\mathrm{pH}$ has wide applicability for different woody biomass.

\section{Crystallinity Analysis}

Previous studies showed that a small amount of cellulose is dissolved and degraded during hydrothermal pretreatment. Here, the effect on the structure of cellulose was analyzed by determining the crystallinity index (CrI) of RM, THP, and HP. The results are 
shown in Fig. 4. Two peaks at $2 \theta=16.5^{\circ}$ and $2 \theta=22.5^{\circ}$ were attributed to the typical cellulose-I structure scattering intensity (Jonoobi et al. 2015; Kamthai and Magaraphan 2017; Mohomane et al. 2017). The peak position did not change, and the CrI increased from $60.5 \%$ to $62.1 \%$ after THP. This is due to the dissolution of a large amount of hemicellulose and a small amount of cellulose in pretreatment (Golbaghi et al. 2017). In addition, the CrI of HP was $64.2 \%$. Compared with THP, the CrI of HP was larger. This result shows that hemicellulose extraction was promoted, and the dissolution and degradation of cellulose were inhibited. The structure of the cellulose was protected in hydrothermal pretreatment with pre-adjustment $\mathrm{pH}(\mathrm{pH} 4.0)$. The cellulose content in $\mathrm{RS}$ after pretreatment was higher.

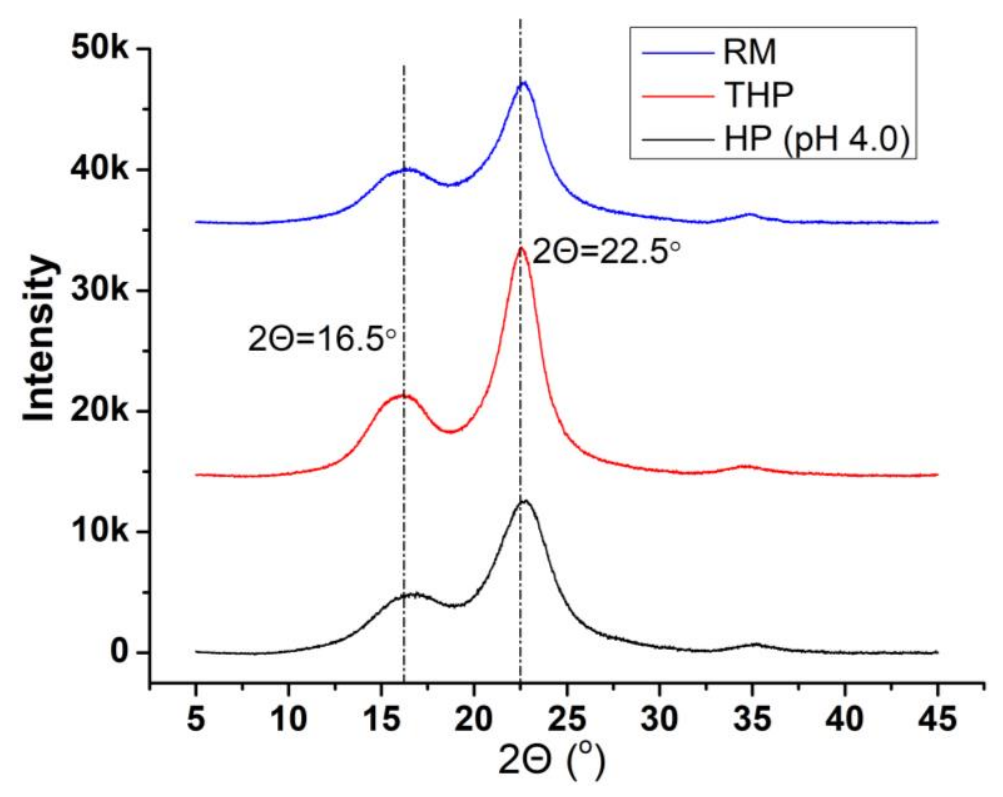

Fig. 4. Crl of eucalyptus with or without pretreatment

\section{Analysis of Lignin Structure}

The above studies showed that lignin dissolution and degradation were inhibited

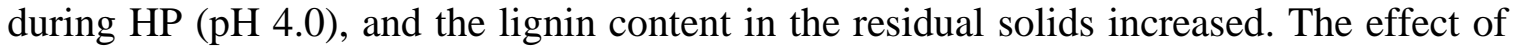
lignin dissolution and degradation on structure was analyzed by 2D-HSQC-NMR, as shown in Fig. 5. The HSQC cross-signals of lignin were compared with reference data (Sun et al. 2015; Chen et al. 2019). The lignin side-chain signals of eucalyptus (Fig. 5a) were mainly OMe, $\beta-\mathrm{O}-4$, phenylcoumarane, and resinol. The main lignin structural units of eucalyptus were $\mathrm{S}$-unit and G-unit. The signals $\mathrm{S}_{2,6}$ and $\mathrm{S}_{2,6}^{\prime}$ from $\mathrm{S}$-unit were observed at

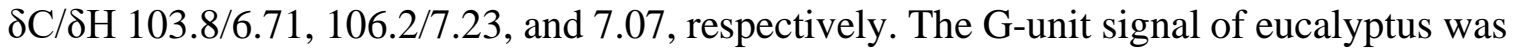
mainly including $\mathrm{G}_{2}, \mathrm{G}_{5}$, and $\mathrm{G}_{6}$. All signals were weakened (Fig. 5b) after THP. Thus, the eucalyptus lignin structure was dissociated during the THP process. This result was consistent with the changes in lignin content. However, the signals $S_{2,6}, S_{2,6}^{\prime}, O M e, C \gamma$ and $\mathrm{A} \beta(\mathrm{s})$ were enhanced compared with HP (Fig. 5c), indicating that the $\beta-\mathrm{O}-4$ bonds, OMe, and phenylcoumarane in G-unit and S-unit were protected. The results showed that the structural dissociation of eucalyptus lignin was inhibited in hydrothermal pretreatment with pre-adjustment $\mathrm{pH}$ ( $\mathrm{pH} 4.0)$. 


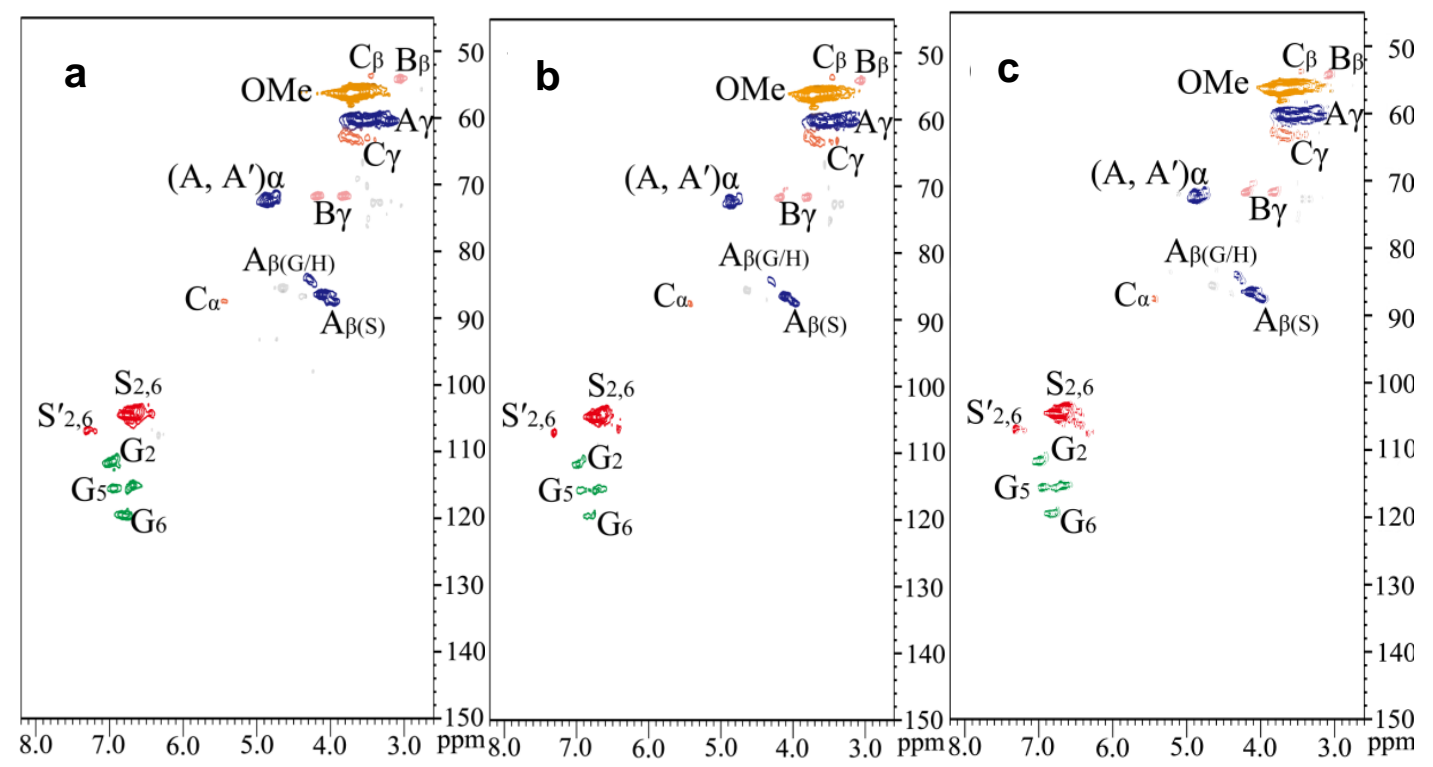

Fig. 5. 2D-HSQC NMR spectra of eucalyptus (a: RM; b: THP; c: HP)

\section{CONCLUSIONS}

1. The extraction efficiency of eucalyptus hemicellulose was improved in hydrothermal pretreatment with pre-adjustment $\mathrm{pH}(\mathrm{pH} 4.0)$. The extracted hemicellulose was mainly in the form of oligose. The content of cellulose and lignin in hydrolysate was lower.

2. The pretreatment was conducive to the effective separation and purification of hemicellulose. The eucalyptus had higher CrI after pretreatment. The structural dissociation of lignin was inhibited. The results show that the hydrothermal pretreatment with pre-adjustment $\mathrm{pH}$ has wide applicability for different woody biomass.

\section{ACKNOWLEDGMENTS}

This project was sponsored by the National Natural Science Foundation of China (21968004) and the Guangxi Natural Science Foundation of China (2018GXNSFDA281050).

\section{REFERENCES CITED}

Amidon, T. E., and Liu, S. (2009). "Water-based woody biorefinery," Biotechnol. Adv. 27(5), 542-550.

Batalha, L. A. R., Han, Q., Jameel, H., Chang, H. M., Colodette, J. L., and Gomes, F. J. B. (2015). "Production of fermentable sugars from sugarcane bagasse by enzymatic hydrolysis after autohydrolysis and mechanical refining," Bioresource Technol. 180, 97-105.

Cebreiros, F., Ferrari, M.D., and Lareo, C. (2018). “Combined autohydrolysis and alkali 
pretreatments for cellulose enzymatic hydrolysis of Eucalyptus grandis wood," Biomass Convers. Bior. 8(1), 33-42.

Chandra, R. P., Gourlay, K., Kim, C.-S., and Saddler, J. N. (2015). "Enhancing hemicellulose recovery and the enzymatic hydrolysis of cellulose by adding lignosulfonates during the two-stage steam pretreatment of poplar," ACS Sustain. Chem. Eng. 3(5), 986-991.

Chen, W. J., Zhao, B. C., Cao, X. F., Yuan, T.Q., Shi, Q., Wang, S. F., and Sun, R. C. (2019). "Structural features of alkaline dioxane lignin and residual lignin from Eucalyptus grandis x E. urophylla," J. Agr. Food Chem. 67(3), 968-974.

Chen, X. W., Lawoko, M., and van Heiningen, A. (2010). "Kinetics and mechanism of autohydrolysis of hardwoods," Bioresource Technol. 101(20), 7812-7819.

French, A. D., and Cintron, M. S. (2013). "Cellulose polymorphy, crystallite size, and the Segal Crystallinity Index," Cellulose 20(1), 583-588.

Ge, J., Wu, Y., Han, Y., Qin, C., Nie, S., Liu, S., Wang, S., and Yao, S. (2020). "Effect of hydrothermal pretreatment on the demineralization and thermal degradation behavior of eucalyptus," Bioresource Technol. 307, 123246.

Goldmann, W. M., Ahola, J., Mikola, M., and Tanskanen, J. (2017). "Formic acid aided hot water extraction of hemicellulose from European silver birch (Betula pendula) sawdust," Bioresource Technol. 232, 176-182.

Golbaghi, L., Khamforoush, M., and Hatami, T. (2017). "Carboxymethyl cellulose production from sugarcane bagasse with steam explosion pulping: Experimental, modeling, and optimization," Carbohyd. Polym. 174, 780-788.

Huang, L., Yang, Z., Li, M., Liu, Z., Qin, C., Nie, S., and Yao, S. (2020). "Effect of precorrected $\mathrm{pH}$ on the carbohydrate hydrolysis of bamboo during hydrothermal pretreatment," Polymers 12(3), 612.

Jiang, H., Chen, Q., Ge, J., and Zhang, Y. (2014). "Efficient extraction and characterization of polymeric hemicelluloses from hybrid poplar," Carbohyd. Polym. 101, 1005-1012.

Jonoobi, M., Oladi, R., Davoudpour, Y., Oksman, K., Dufresne, A., Hamzeh, Y., and Davoodi, R. (2015). "Different preparation methods and properties of nanostructured cellulose from various natural resources and residues: A review," Cellulose 22(2), 935-969.

Kamthai, S., and Magaraphan, R. (2017). "Mechanical and barrier properties of spray dried carboxymethyl cellulose (CMC) film from bleached bagasse pulp," Ind. Crop. Prod. 109, 753-761.

Kaur, P., Bhardwaj, N. K., and Sharma, J. (2016). "Pretreatment with xylanase and its significance in hemicellulose removal from mixed hardwood kraft pulp as a process step for viscose," Carbohyd. Polym. 145, 95-102.

Li, H. M., Saeed, A., Jahan, M. S., Ni, Y. H., and van Heiningen, A. (2010). "Hemicellulose removal from hardwood chips in the pre-hydrolysis step of the kraftbased dissolving pulp production process," J. Wood Chem. Technol. 30(1), 48-60.

Liu, S., Lu, H., Hu, R., Shupe, A., Lin, L., and Liang, B. (2012). “A sustainable woody biomass biorefinery," Biotechnol. Adv. 30, 785-810.

Liu, Y., Sun, B., Zheng, X., Yu, L., and Li, J. (2018). "Integrated microwave and alkaline treatment for the separation between hemicelluloses and cellulose from cellulosic fibers," Bioresource Technol. 247, 859-863.

Mohomane, S. M., Motaung, T. E., and Revaprasadu, N. (2017). "Thermal degradation kinetics of sugarcane bagasse and soft wood cellulose," Materials 10(11), 12. 
Persson, T., Ren, J. L., Joelsson, E., and Jonsson, A. S. (2009). "Fractionation of wheat and barley straw to access high-molecular-mass hemicelluloses prior to ethanol production," Bioresource Technol. 100(17), 3906-3913.

Santos, T. M., Alonso, M. V., Oliet, M., Dominguez, J. C., Rigual, V., and Rodriguez, F. (2018). "Effect of autohydrolysis on Pinus radiata wood for hemicellulose extraction," Carbohyd. Polym. 194, 285-293.

Sluiter, A., Hames, B., Ruiz, R., Scarlata, C., Sluiter, J., Templeton, D., and Crocker, D. (2012). Determination of Structural Carbohydrates and Lignin in Biomass (NREL/TP-510-42618), National Renewable Energy Laboratory, Golden, CO, USA.

Song, T., Pranovich, A., and Holmbom, B. (2011). "Effects of $\mathrm{pH}$ control with phthalate buffers on hot-water extraction of hemicelluloses from spruce wood," Bioresource Technol. 102(22), 10518-10523.

Sun, Y.C., Wang, M., and Sun, R.C. (2015). "Toward an understanding of inhomogeneities in structure of lignin in green solvents biorefinery. Part 1: Fractionation and characterization of lignin," ACS Sustain. Chem. Eng. 3(10), 24432451.

Trajano, H. L., Engle, N. L., Foston, M., Ragauskas, A. J., Tschaplinski, T. J., and Wyman, C. E. (2013). "The fate of lignin during hydrothermal pretreatment," Biotechnol. Biofuels 6, 16.

Whitfield, M. B., Chinn, M. S., and Veal, M. W. (2016). "Improvement of acid hydrolysis procedures for the composition analysis of herbaceous biomass," Energ. Fuel. 30(10), 8260-8269.

Yao, S., Nie, S., Yuan, Y., Wang, S., and Qin, C. (2015). "Efficient extraction of bagasse hemicelluloses and characterization of solid remainder," Bioresource Technol. 185, 21-27.

Yao, S., Nie, S., Zhu, H., Wang, S., Song, X., and Qin, C. (2017). "Extraction of hemicellulose by hot water to reduce adsorbable organic halogen formation in chlorine dioxide bleaching of bagasse pulp," Ind. Crop. Prod. 96, 178-185.

Yuan, T. Q., Sun, S. N., Xu, F., Sun, and R. C. (2011). "Characterization of lignin structures and lignin-carbohydrate complex (LCC) linkages by quantitative C-13 and 2D HSQC NMR spectroscopy," J. Agr. Food Chem. 59(19), 10604-10614.

Zhang, K., Pei, Z. J., and Wang, D. H. (2016). "Organic solvent pretreatment of lignocellulosic biomass for biofuels and biochemicals: A review," Bioresour Technol. 199, 21-33.

Zhou, X. L., Liu, J., Huang, T. J., Bian. H. Y., Wang, R. B., Sha, J. L., and Dai, H. Q. (2020). "Near-complete enzymatic hydrolysis efficiency of Miscanthus using hydrotropic fractionation at atmospheric pressure," Ind. Crop. Prod. 149, 112365.

Zhuang, X. S., Wang, W., Yu, Q., Qi, W., Wang, Q., Tan, X. S., Zhou, G. X., and Yuan, Z. H. (2016). "Liquid hot water pretreatment of lignocellulosic biomass for bioethanol production accompanying with high valuable products," Bioresource Technol. 199, $68-75$.

Article submitted: May 27, 2020; Peer review completed: July 4, 2020; Revised version received and accepted: July 5, 2020; Published: July 9, 2020.

DOI: 10.15376/biores. 15.3.6627-6635 